\title{
COMUNAL ESTÉREO, RADIO DE BARRIO EXPRESIÓN SONORA DE LAS OTRAS CIUDADANÍAS. SISTEMATIZACIÓN
}

Por:

\author{
Jorge Caicedo ${ }^{1}$ \\ Profesor de la Esculela de Comunicación Social \\ Universidad del Valle \\ Cali, Colombia \\ jkaicedo@codicecomunicaciones.org
}

\section{Resumen:}

Este artículo da cuenta del proceso de sistematización de la experiencia de radiodifusión comunitaria urbana Comunal Estéreo, de la comuna 10 de Cali, en Colombia. En junio del 2001, y luego de construirse en un marco de legitimidad dada por el trabajo de base durante 15 años, pero desde la ilegalidad a la que la ausencia de políticas públicas claras en este sentido le habían arrojado, fue condenado al cierre inmediato, al silencio y a la espera de un proceso de licitación mediante el cual pudiera volver al aire. Diez años después del cierre, una vez abierto y desarrollado el proceso de licitación pública, recibió la notificación estatal de que su proyecto no era viable para acceder a la licencia de transmisión durante la próxima década en medio de un oscuro proceso de escogencia legal. Quedaba así, por fuera de toda posibilidad de acceder al derecho a la comunicación, un proceso construido a pulso de muchas voluntades y de mucho tiempo. Hoy, en el marco de su silencio absoluto y aparentemente definitivo se hace necesaria su revisión de un proceso que exploró nuevas formas de hacer la comunicación radial. Recuperamos y sistematizamos esta experiencia como un aporte para el movimiento de las radios populares o comunitarias en Colombia.

\section{Palabras Claves:}

Radio comunitaria, comunicación popular, participación comunitaria, movilización social, derecho a la comunicación, ciudadanía.

\footnotetext{
${ }^{1}$ Comunicador social - Especialista en Desarrollo Comunitario. Profesional Corporación Códice Comunicaciones
} 
De otra parte, procesos conformados por las vías de hecho y no del derecho, espacios que habían logrado su legitimidad a fuerza del trabajo diario en las calles y en el corazón de los problemas de la cotidianidad, tuvieron que marginarse o aliarse con otras organizaciones, pues la ley les exigía por lo menos cuatro años de existencia legal $^{3}$. Otro resultado de la experiencia licitatoria fue la atomización del proceso. Cada colectivo que hasta esa fecha le apostó a una radio comunitaria e intentó con ella generar procesos de visibilización de su entorno más próximo hacia el resto de la ciudad vio frustrada esta intención política, pues la disposición estatal, antes que aprobar licencias para radios de cobertura total de la ciudad, le apostó a la fragmentación del contexto territorial, dividiéndolo en micro-universos desde los cuales la gente podría producir su radio, sin exceder límites territoriales cercanos en su emisión; es decir, la des-conexión general del tejido social que se venía construyendo desde otros ámbitos. Así, Bogotá se dividió en siete sub-contextos para siete emisoras de bajo alcance, Cali en cinco, Medellín en cuatro, Barranquilla en tres y otras quince capitales de departamentos, ciudades como Pereira, Armenia, Villavicencio, Manizales entre otras, se dividieron en dos zonas. Lo que aparentemente podría ser leído como la democratización del derecho a la comunicación al incluir más estaciones radiales por ciudad, se convertía en una estrategia de desconexión general, de atomización del movimiento de la comunicación popular en cada contexto, con el agravante de que de las 21 posibles nuevas estaciones, tan solo unas pocas fueron asignadas en todo el país. Las plazas que fueron declaradas desiertas, probablemente tendrán que esperar otros 10 años, para que puedan volver a plantearse como una posibilidad.

\section{Por qué mirar cómo hacer otra radio...}

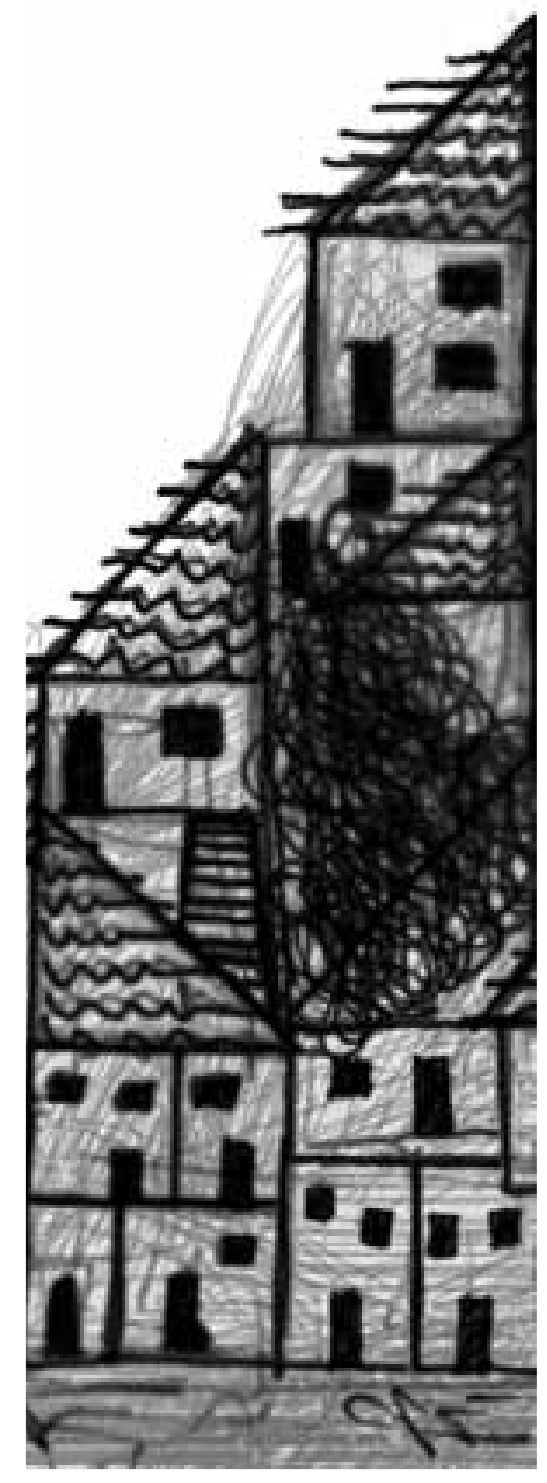

Sistematizar, en palabras de Oscar $\mathrm{Jara}^{4}$, se refiere a la recuperación a través de la memoria colectiva, de aquellas experiencias vitales, entendidas como procesos socio-históricos, dinámicos y complejos, individuales y colectivos, que son vividos por personas concretas en momentos históricos puntuales; este ejercicio, más que la mera sistematización de información, tiene toda una intención política y científica, dado que busca ante todo, realizar una interpretación crítica de un proceso, extraer aprendizajes y generar un nuevo conocimiento que derive en fundamentos aplicables a procesos similares actuales y futuros ${ }^{5}$.

En este contexto, el proyecto de investigación/sistematización que hemos emprendido, busca encontrar algunas claves para entender la conformación y el desarrollo de procesos de radiodifusión en contextos urbanos colombianos de mediana y gran envergadura; esto, en momentos en que la legalidad y la posibilidad se hace inminente a partir de los procesos de licitación adelantados desde 2007 que incluyeron a las ciudades capitales de departamento. 
Muchas son las discusiones que se han iniciado, seguido, terminado y re-abierto en torno a la forma o las formas de denominar estos procesos de comunicación, diferentes en su concepción y modo de desarrollo, comunicación surgida en la mayoría de los casos, desde intereses particulares que responden a situaciones sociohistóricas definidas. En el caso de Colombia, por ejemplo, el término asociado a lo comunitario, ha sido acuñado con tanta fuerza que hace parte de la manera como el mismo ministerio encargado de las comunicaciones ${ }^{10}$ divide las opciones de hacer radio en Colombia ${ }^{11}$. En el marco de estas discusiones/construcciones, se plantea el término Radio Comunitaria concebida como una radio ecléctica ${ }^{12}$, en la que cabe todo, pero que debe hacer uso de un eje o hilo conductor; una radio que se construye desde la riqueza de lo diverso que confluye en intereses comunes relacionados con la falta de espacio y visibilidad, la poca oportunidad o la excluyente caracterización de los mensajes radiofónicos y no radiofónicos.

Hablamos entonces de una radio que, en palabras del mismo Leonel Yáñez (2004), radialista y analista chileno, debe ser vista no como un fenómeno menor o casual, sino como

una práctica y producción cultural de unos sujetos y organizaciones que debe ser observado como un fenómeno no menor, y quizá... como un lugar que puede constituirse o consolidarse (cristalizar) en un movimiento social (es decir, que congrega a distintos sujetos bajo una identidad e intenciones políticas, reivindicativas) $)^{13}$.

Otras clasificaciones que la describen pero no necesariamente la identifican de manera consensual, tienen que ver con la forma como se organiza y se adelantan sus procesos de producción. John Downing, quien se ha especializado en estos fenómenos de comunicación alternativos, prefiere usar el término medios radicales, asumiendo tanto su postura frente a la realidad en la que surgen y contra la que deben actuar, como las condiciones como sobrevive y se sostiene ${ }^{14}$. Habla entonces de medios pequeños, de cuya calidad no es muy pertinente detenerse a revisar, pues más allá de cómo suenan, debe atenderse el para qué lo hacen. Esta postura hace que de alguna manera, muchos espacios sean encasillados desde moldes rígidos que hacen que la estética particular, sea relacionada con formas poco ortodoxas y sonoramente deficientes. Esto conlleva, de manera contraria, a que experiencias que se preocupan por la forma, independiente de posturas políticas y de resistencia claras, puedan no ser consideradas dentro de este marco. Es el caso de Comunal Estéreo. Guiada por procesos de formación que auto-gestionó y por la suma de experiencias individuales anteriores de sus actores, muchos de los cuales pasaron por procesos de radio comercial, esta emisora cuidaba mucho su sonido y la innovación en sus discursos. Mucho después de su surgimiento, en 1996 y con una cobertura definida por la fuerza de su transmisor hechizo y la altura de la guadua que sostenía la antena de cobre, avanzó hacia el cubrimiento físico de toda la ciudad, en contraposición a lo que Downig considera clave en la delimitación de este tipo de medios: la baja cobertura. 
En este sentido, la experiencia demuestra que si bien, esta condición es la constante en el origen de la mayoría de los procesos alternativos de radio que se inician desde megáfonos, altoparlantes colgados en postes de madera, transmisores de baja potencia y poca cobertura, luego, sus propios desarrollos hacen que se avance hacia un crecimiento técnico de la mano de la legitimidad de su hacer, así la legalidad sólo aparezca en contadas ocasiones ${ }^{15}$.

La comunicación popular también enmarca en sus linderos este tipo de radio y sus discursos. Se habla entonces de una radio en la que la participación tiene un accionar protagónico, participación concebida como la posibilidad de darle voz a las mayorías o a las minorías silenciadas históricamente y condenadas a una postura de oyentes pasivos. Rosa María Alfaro planteaba hace mucho tiempo esta relación muy ligada a la capacidad educativa, formativa, transformadora de los mismos procesos de radiodifusión. Una comunicación pensada para grupos pequeños, con una finalidad central comunicativa, pero entroncada en la educación popular y con un actor clave, el comunicador, entendido no como ese personaje privilegiado con acceso a las escuelas, sino todo aquel con la posibilidad y la necesidad de decir, con una misión clave de vehicular hacia la liberación ideológica del pueblo/auditorio. En pocas palabras: una comunicación para una sociedad en la que es imperativo abonar el terreno para la transformación global del sistema social, sin tener que esperar las grandes revoluciones. ${ }^{16}$

En resumen, podemos decir que lo importante acá no es llegar a una definición que recoja la totalidad de experiencias, una clasificación arbitraria por demás que termine juzgando qué experiencias lo son y cuáles no. Más importante que esto, es detectar las múltiples posibilidades en su decir y en su hacer que comportan estos procesos. Cicilia Peruzzo anota en este punto la necesidad de no caer en la macartización de los procesos, pues en razón de esta diversidad, hay que tener cuidado en la clasificación. No es necesario que una única experiencia comporte al mismo tiempo todas las dimensiones apuntadas. Hacer comunicación comunitaria implica un proceso que tiende al perfeccionamiento progresivo, sobre todo, cuando es asumido colectivamente $^{17}$. Algunas experiencias le apuestan más a la construcción de un elemento de participación claro, mientras otras, sin abrirse demasiado, le apuestan a la transformación desde núcleos humanos pequeños pero con grandes alcances. Comunal, en nuestro caso, es una extraña mezcla de unos y otros elementos: es un grupo relativamente pequeño jalonando las directrices de su acción, pero unas transformaciones que en mayor o menor medida, alcanzaron a marcar las formas de asumir la vida por parte de instituciones, organizaciones, grandes colectivos, individuos y la misma radio caleña. Son la democratización de la comunicación desde la práctica que surge como respuesta a la necesidad de transformar unos medios tradicionales que no generan sensaciones de representación en la gente ${ }^{18}$. 


\section{Los orígenes}

Radios como Comunal Estéreo son el resultado o la respuesta a una carencia, a un problema o a una posibilidad. Históricamente, su aparición en el mundo está ligada a los movimientos de mayo del 68 en Europa. Allí se da vida a muchas expresiones libertarias, entre ellas, a las denominadas radios libres con una primera experiencia en Italia; en este país una estación radial pequeña puso en jaque todo el sistema de radio comercial, dejando que la gente común accediera a la producción de radio ${ }^{19}$.

En el caso de nuestra experiencia, un cúmulo de carencias, olvidos, ausencias, rupturas y la presencia del agua que inundaba las calles y casas de un sector popular en la ciudad, motivó la necesidad de gritar, de contarle al resto del mundo el problema, de llamar la atención a quienes correspondiese una solución. Surgieron los megáfonos, los altoparlantes, el sonido ronco artesanalmente musicalizado y el ruido imposible de anular en el aire y en los oídos de todos y cada uno de los habitantes de esa zona de la ciudad. Estos sonidos, que por momentos se usaron para adelantar estrategias urgentes, para evitar desastres y pérdidas más grandes por los "pequeños tsunamis $^{20}$ " que producía el apresamiento de las aguas lluvias, configuraron el embrión de lo que a futuro se convertiría en una de las muchas experiencias de radio popular en Cali.

Esta ciudad se debatía entre los estragos del narcotráfico que la pintaba mundialmente y los vacíos de una legislación en comunicación que no alcanzaba a comprender la dimensión ni la necesidad de estos espacios radiales. Jesús Martín Barbero define este tiempo como un segundo momento de la comunicación en Colombia, a partir de la conformación de medios públicos, llamados a sustituir el espacio del debate público y ciudadano que en los medios comerciales se perdió, de la mano de intereses particulares y estatales $^{21}$.
Es la misma historia que se repite en cada contexto en el que la otra radio hace presencia y gana protagonismo. Una radio llamada a reivindicar el derecho a la palabra y a la comunicación, una radio que como la define Rosalía Winocur está llamada a conformar al individuo en su condición de ciudadano, a partir de nuevas formas de concebir esta noción ${ }^{22}$, más allá de la mirada reduccionista que lo convierte en estadística, potencial votante o portador de una cédula. Una ciudadanía que en su despertar, deja aflorar en distintas latitudes, la humanidad en todas las posibles dimensiones ocultadas o resignadas por la mirada hegemónica que se emite en las radios del sistema oficial. Frente a esta intencionalidad consciente e interesada de reducir a la gente en su dimensión de consumidor, María Cristina Mata se manifiesta cuando describe el caso argentino post-dictadura, tiempo en el que los sistemas de comunicación manejados por el gobierno militar, especialmente la radio, anularon cualquier dimensión humana ajena que pudiese poner en peligro el estatus quo establecido desde las milicias regentes del poder ${ }^{23}$.

Una rápida mirada al panorama latinoamericano, colombiano y local da cuenta de esta re-escritura del rol del ciudadano. Colombia con sus experiencias de emisoras educativas en elValle de Tenza, con la red de emisoras del Pacífico bajo el proyecto Playdecop y la posterior aparición de redes de radio nacionales como Recorra, Andares, Aredmag, la red de radios indígenas y en un menor impacto, Redecom en elValle del Cauca; Bolivia con sus radios mineras que reivindicaban los derechos de los hombres y mujeres que escarban el corazón de la tierra en busca del estaño de otros; en la Argentina, surgen como radios de baja potencia e inundan el FM una vez la democracia regresa al panorama social del país, y como inmediata reacción a la represión informativa que imponía la dictadura militar; pero a diferencia de los movimientos de las otras naciones, que respondían más a procesos sociales organizados, acá lo que las guió fue la anarquía. En el Brasil, aparecen como radios libres, ubicadas en los suburbios de las principales ciudades, generando reacción en las grandes cadenas comerciales que aliadas con el Estado, adelantan toda una estrategia 
de represión y decomiso ${ }^{24}$; En Venezuela, los años 90 son testigos del surgimiento de experiencias como Radio Convite, Radio Perola y Radio Catía, de la mano de los procesos populares con gran incidencia en la política de este país; mientras que en Ecuador, a finales de los 80, de la mano de la Asociación Latinoamericana de Educación Radiofónica-ALER, las radios populares surgieron de manera lenta, pero poco a poco tomaron gran fuerza convirtiéndose más adelante en la sede continental para la Asociación Mundial de Radios Comunitarias-AMARC ${ }^{25}$.

En Cali, los años 80 le dieron espacio a experiencias como Estrella Estéreo en la zona de ladera, en el legendario espacio de Siloé que ha vivido importantes estadios de la vida de la ciudad como la presencia fuerte del M-19 y su posterior desalojo a sangre y fuego, una emisora que se ha ido transformando bajo otros nombres y moviéndose de manera itinerante y clandestina, reivindicando su derecho a la comunicación desde la ilegalidad, pero desde la legitimidad que la comunidad le brinda. Aguablanca Estéreo, en el Oriente de la ciudad, surgiría en los 90's motivada por los intereses de generar proyectos de comunicación para la movilización social en salud, pero sería presa de las malas intenciones de algunos líderes comunitarios y el espíritu mercachifle de algunos comunicadores de los medios tradicionales. Éstos terminaron dilapidando el presupuesto y enviando el proceso a la intervención fiscal y al cierre definitivo; Alternativa Estéreo, en la zona del Sur Oriente de la ciudad, surgiría de la mano de la casa de la Juventud del barrio La Unión y alcanzaría a construir importantes procesos de tejido social; pero moriría, al igual que Comunal, en el proceso licitatorio del 2008; Culturama Estéreo en la comuna 3, surgió desde el impulso de jóvenes estudiantes de locución que han logrado mantener un espacio de construcción y expresión; y ante la negativa estatal ha tenido que migrar hacia otros espacios de visibilidad y resistencia, como el cine comunitario. Finalmente, toda una serie de pequeñas experiencias generadas desde el altoparlante como la Emisora Popular Alternativa-EPA, en el sector de Manuela Beltran o la escuela radial alternativa de Paz Estéreo, en el barrio La Paz, del Distrito de Aguablanca. Distintas formas de asumir desde lo sonoro y la organización, la responsabilidad de ubicar a comunidades históricamente excluidas, en el centro de la sociedad de la información y la comunicación, desde una comunicación ciudadana ${ }^{26}$.

\section{La línea de vida de Comunal Estéreo}

A través de los relatos encontrados en los y las protagonistas de la historia de la radio en cuestión, se puede identificar como el proceso de construcción de una radio comunitaria, es ante todo un espacio de lucha, resistencia, re-escritura y rediseño de la experiencia y construcción de una dimensión particular para cada proceso; de ahí lo complejo de alcanzar una definición general. Comunal tiene su génesis desde varios factores. Una serie de experiencias individuales que desde distintos espacios se acercaron a la radio con otras formas de concebirla, distintas a la tradicional: líderes que encontraron en la oralidad la manera más importante de alcanzar atención, lograr una especie de seducción en el auditorio y gestar una posterior disposición a la movilización; una serie de jóvenes que desde sus expectativas profesionales, personales, oníricas y laborales, habían pensado en la radio como un fin y un medio; jóvenes estudiantes de academias de locución de 
garaje o medianamente organizadas, jóvenes que se formaban de manera empírica bajo la tutela de las radios comerciales que les canjeaban educación no formal por trabajo, y otros que sin pasar por estas circunstancias y en su calidad de permanentes oyentes, jugaban a hacer radio y vieron en esta experiencia la posibilidad de cambiar los micrófonos de palo o invisibles por "los de verdad". Finalmente, un grupo de profesionales de distintas disciplinas, incluida la comunicación social, que descontentos por las posibilidades expresivas y profesionales del medio, buscaron nuevas formas de incidir con sus saberes en el desarrollo de una comunidad a la que hacían parte. A estos elementos humanos, se les suma la condición detonante natural de la carencia, de la situación que debe y puede ser transformada y en la que la radio, puede jugar un papel importante.

La radio se inicia entonces como una experiencia incipiente de expresión sonora, tanto en la técnica como en la forma y fondo de los contenidos. Primero se orienta a la comunidad sobre la presencia del problema, las inundaciones en este caso, luego se avanza en procesos organizativos para generar una acción popular que a partir de reuniones en el espacio comunitario y luego mediante movilizaciones hacia las instancias decisorias del gobierno municipal, logran presionar y generar acciones que dan solución al problema. Luego, el espacio de comunicación es reivindicado por la organización social y alcanza otra serie de dimensiones y usos sociales que lo acercan a la condición de movimiento social: la conexión entre habitantes que estando en un mismo espacio, poco se ven; la divulgación de acciones que generándose en el espacio, difícilmente son apropiadas por la gente; el descubrimiento de talentos naturales que desde otras vías como la radio tradicional, difícilmente podrán ser vistos (escuchados). La iniciativa de comunicación entonces, gana legitimidad y un importante espacio que lo convierte en parte del paisaje y la rutina comunitaria.

Esta radio que circula libre desde los altoparlantes, es también la onda sonora que no permite la escogencia libre y autónoma; es la radio que se escucha o se escucha. Con el tiempo la comunidad que se sirve de ella plantea una relación tirante cuando la impertinencia de la señal rompe rutinas que no quieren ser quebrantadas. Entonces es necesario avanzar hacia otros canales. La radio viajando por el espectro es la opción; Comunal ingresó al espectro electromagnético en 1996, a partir de un proceso de alianza con un programa de reinserción del EPL $^{27}$ con el Estado y con el acompañamiento de algunos profesionales de la Universidad del Valle que veníamos desencantados de la radio tradicional; en este momento, a través de un transmisor hechizo y una antena soportada en una guadua, se emitió desde la frecuencia 97,4 FM, irregularmente autorizada ${ }^{28}$ y con una cobertura pequeña pero suficiente para generar un público oyente y para atraer nuevas voluntades a sumarse al proceso.

La radio desde el hogar, hecha sin las especificaciones técnicas mínimas y alternando sus sonidos con las rutinas propias de un hogar: un almuerzo que se hace con una olla a presión que sale de fondo a la emisión, los llantos de los nuevos bebés que no entienden aquello de "silencio, vamos al aire", un cabina de grabación que ocupa el mismo sitio que el cuarto de los equipos, que el rincón de los chécheres y la pieza donde se plancha la ropa de los dueños de casa; también una lavadora que está allí, siempre, de fondo a las noticias que se leen del periódico popular del día y de las revistas de variedades que los participantes donan a la causa.

En 1998, la radio abandona su artesanal sede y comienza a emitir desde la Casa Comunal del barrio San Judas en la comuna 10; el número de participantes aumenta de 27 a casi 70 y la programación se nutre con nuevos espacios, mucho más estructurados pero aún incipientes. Luego, los profesionales de la Universidad del Valle que los acompañamos en los talleres iniciales, volvimos y ayudamos, en conjunto con el colectivo líder a organizar el asunto: un nuevo proceso de capacitación que trabaja sobre diseño y escritura radiofónica, sobre ciudadanía y liderazgo y sobre expresión corporal y gestión; se dio el cierre de la emisora por tres meses y su relanzamiento con cubrimiento total a la ciudad a raíz de la ubicación de su transmisor en los cerros tutelares; hay una organización que responde a estructuras administrativas convencionales pero que funciona con 
departamentos de producción, administrativo, ventas, técnico y de extensión; se logra una ampliación de la programación a 24 horas y la construcción de una parrilla de contenidos que incluye informativos, programas de variedades, consultorios jurídicos, médicos y hasta espirituales; programas deportivos transmiten fútbol profesional de manera clandestina desde una cabina abandonada en el Estadio de la ciudad o desde la transmisión de televisión que se hace por la tv satelital; programas musicales exploran manifestaciones poco visibles (audibles) en la radio tradicional: la música del Pacífico que luego aportaría al gran impulso que tuvo el festival Petronio Álvarez, el Rap que llevó a sus instalaciones a artistas anónimos para la fecha como Los Generales, Junior Jeim y el mismo Choc-Qui-Town (mucho después se ganaría el Grammy); el Rock de las bandas locales, la Nueva Trova cubana, el tango, la música andina y otras manifestaciones que después tuvieron sitio en radios comerciales que hasta ese momento, poco habían arriesgado en su difusión.

Este proceso duró hasta el 30 de Junio de 2001, cuando la presión de las empresas privadas de comunicación radiofónica y el acoso del Estado con su Ministerio de Comunicaciones, derivaron en el cierre provisional de la estación, días antes del establecimiento de la ley 599 de 2000 que establecía la entrada en vigencia a partir del 1 de Julio de 2001, del nuevo Código Penal, en el que el nuevo estatuto de comunicación, daba el carácter de delito encarcelable a todo acto de emisión radiofónica sin la correspondiente licencia de transmisión.

Diez años después del cierre, ACORADIO, la organización creada para soportar legalmente la emisora, se ha dedicado a acompañar otros procesos de producción radiofónica con comunidades indígenas como la del resguardo de Canoas en el Cauca y la de la ACIVA $\mathrm{RP}^{29}$ en Buenaventura; afrocolombianas como la comunidad de Villarrica en el Cauca y Villapaz en el norte del Valle; académicas como las emisoras estudiantiles de secundaria de las instituciones educativas “José María Vivas Balcázar” en la comuna 10 y "Celmira Bueno" en la comuna urbana número 5; igualmente, ha participado en procesos de redes ciudadanas como Enredémonos por lo sano y
Cali de Vida, agenciadas por la Universidad del Valle y la Red Municipal del Buen Trato de la Secretaría de Salud Municipal.

Diez años después, también, ACORADIO, a partir de la lucha nacional por el derecho a la comunicación encabezada por RECORRA, participó en el proceso de licitación pública para acceder a la licencia de radiodifusión comunitaria en la zona 3 de Cali y pese a la experiencia, a la organización, al tejido social creado durante más de 20 años y al deseo manifiesto de continuar con su trabajo de desarrollo comunitario, la licencia le fue negada y su historia, condenada a un silencio que se plantea definitivo.

\section{Algunas dimensiones iniciales de análisis para el proceso}

Esta experiencia ha sido reconstruida desde el relato colectivo. Hace unos años, justo en el momento en que Comunal cerraba su voz, el chileno Leonel Yáñez, hacía una división en ámbitos de análisis para re-conocer las prácticas de los procesos de radio comunitaria y para intentar entender el alcance de las mismas. Proponía entender cada experiencia en torno a tres momentos claves: la radio como elemento dinamizador de procesos organizativos en los territorios donde surgía, la radio como espacio generador de opinión pública en torno a los discursos pensados, elaborados y emitidos y como tercer punto, la radio en relación con el territorio y la generación y consolidación de identidades ${ }^{30}$.

En torno a lo primero: la experiencia. Comunal Estéreo pudo construir a lo largo de su historia una suerte de teoría de la organización y la administración de un medio de comunicación ciudadana, en un contexto territorial en el que los antecedentes en este sentido, eran pocos y bastante intuitivos. La necesidad de crecer tanto en su cobertura como en la complejidad de sus acciones y discursos, hizo que el proceso se convirtiera en un taller de aprendizaje en el que las necesidades puntuales le daban vida a soluciones puntuales. Las necesidades de comunicación y la emotividad que produce la tecno- 
fascinación ${ }^{31}$ por asumir la producción de medios de comunicación por parte de la comunidad que histórica y socialmente ha estado excluida de ellos, le da pie a la construcción de tejidos en los que voces y actores diversos, unifican sentidos e intereses; esta convivencia obliga a estructurar formas organizativas que pasan por el establecimiento de comités, departamentos, coordinaciones y los hilos jerárquicos, las líneas de poder y los flujos de comunicación necesarios para que las cosas avancen.

La administración como disciplina es desarrollada a veces de manera empírica y en otras ocasiones con la ayuda de profesionales que sin saber mucho de este ámbito, ajustan sus métodos y procesos; igual ocurre con la contaduría, la economía, la sicología y sobre todo, con la comunicación social. Esta última si bien tiene experticia en desarrollo de mensajes, debe asumir la particularidad de las acciones, los espacios y las regulaciones que el medio impone. Una escuela permanente que nutre tanto a los profesionales que se acercan al proceso como a los propios hacedores de esta otra radio.

Frente a la construcción de una nueva agenda y una nueva forma de concebir y generar la opinión pública, Comunal Estéreo comenzó a generar en la ciudad, la visibilidad de otra serie de realidades que configuraban al barrio y a la comuna como espacios visibles. Clemencia Rodríguez se refiere a esto como el fortalecimiento de los imaginarios culturales locales, el medio descubre e inventa formas de narrar el imaginario cultural a partir de estéticas, formatos y lenguajes locales ${ }^{32}$. En este sentido, los micrófonos y las voces invadieron las canchas de fútbol del barrio El Guabal y su legendario torneo deportivo en el que las viejas glorias terminan sus carreras.

Algunos programas movieron sus equipos humanos y los pocos equipos técnicos y contaron los encuentros de Rap desde los polideportivos del Distrito de Aguablanca o desde las improvisadas tarimas ubicadas en las ciclovías; otros, le dieron espacio a las jornadas ambientales desde barrios como Ciudad Modelo o Floralia en el norte de la ciudad.
Las acciones de las juntas comunales de los barrios vecinos tomaron la dimensión de las agendas de los Concejos municipales y los Congresos nacionales: se volvieron parte clave en la programación de la estación. Las opiniones de los expertos académicos o de funcionarios públicos y decisores, le dieron paso al comentario de esquina materializado en la voz de hombres y mujeres. Los problemas fueron contados desde la óptica particular de quien los vive y no solo de quien los observa en la distancia.

Por último, esas nuevas formas de concebir la ciudadanía y la identidad tuvo la posibilidad sino de configurarse, por lo menos explicitarse, problematizarse y generar una suerte de disposición popular al re-descubrimiento. Allí se pudo generar conciencia de que se pertenece a un espacio y que ese espacio existe y puede ser mostrado hacia afuera; de que la música que produzco o disfruto, trasciende la rumba cercana, la calle y el garaje y gana ahora un espacio en medios como la radio, comienza a configurar organización y movilidad de públicos que refuerzan con ella su sentido de pertenencia y adherencia a una cultura.

Situación similar al proceso anterior ocurrió en la experiencia de Ladera Estéreo cuando desde la radio y desde otras instancias comunitarias, se llamó a la comunidad del sector de Siloé a pintar sus calles y a estampar sus ropas con letreros que le mostraban al resto de la comarca, que pese a la discriminación social y laboral para los habitantes del sector, sus casas y sus ropas lucían coloridos y orgullos letreros de "Yo amo a Siloé". En Comunal por su parte, el sector del Distrito de Aguablanca con sus temas, sus realidades, sus músicas y sus actores, se volvieron parte clave de la programación, generando una especie de redescubrimiento del sector por parte no solo del resto de la ciudad, sino de sus propios habitantes que legitimaron su espacio y de paso, fortalecieron su identificación con el entorno y su condición, haciendo evidente la diferencia, más que como un obstáculo, como una potencialidad ${ }^{33}$. 
En este sentido, sumamos la mirada que Jorge Huergo ${ }^{34}$, apoyado en Paulo Freire, hace de los procesos de comunicación comunitaria cuando invita a identificar la construcción del universo vocabular de la radio y a partir de este, la generación de la voz particular radial, elemento clave para el equipo emisor, y el público sujeto que hace posible conectar desde las ideas, desde los mensajes, el mundo real quebrado, distanciado, que se repele y atomiza en lugares dentro del mismo lugar, en los que la gente poco se ve, poco se encuentra en físico, incluso rehúye al encuentro; la comunicación entendida como ámbito de flujos ${ }^{35}$.

En este sentido, esa voz propia de la que habla Huergo, la que se construye en el día a día, se convierte en el flujo clave que dinamiza y configura un público; una audiencia que se identifica con ese universo vocabular que aparece haciendo audible la conversa cotidiana, la jerga barrial, el suceso normal que no pasa por la muerte o por la sangre, pero que igualmente es importante para la comunidad que lo vive. Una voz propia que además permite la conexión de un universo rico, parte constitutiva de la ciudad, universo que ha sido desconectado, aislado desde otras lógicas. Hablamos de un barrio que se reinventa a través de la expresión sonora y que desde ella se hace presente en el imaginario general. La radio, en palabras de Clemencia Rodríguez, facilitando el encuentro de ciudadanías y de identidades, reconstruyendo o reinventando estos conceptos y redimensionando esa esfera pública a través del encuentro buscado o no, de la amplitud de posibilidades de expresión, de la multiplicidad de narraciones, de la generación de diálogos en muchas vías y de la creación de espacios de concertación físicos y virtuales ${ }^{36}$.

Por último, en lo que respecta al carácter de construcción participativa, es importante mirar la propuesta Comunal, desde la perspectiva que Alvin Tofler planteara en gran parte de su obra ${ }^{37}$ y que otros autores han retomado y enriquecido en torno a la transformación del consumidor a prosumidor de productos y procesos.

La radio que hacía Comunal era hecha por la gente en una serie de experiencias que trascendieron la opinión desde la llamada telefónica o la petición musical. Espacios como "La Sona", que intentaba visibilizar la cultura que construían los jóvenes amantes del hip hop en las zonas de Ladera y Aguablanca, fueron desarrollados directamente por algunos de ellos que iniciaban sus carreras artísticas desde la música y el baile; la salsa denominada de golpe o de barrio, fue visible desde el trabajo de diseño y producción de melómanos y coleccionistas que sin otra experiencia radial que la de oyentes, desarrollaron uno de los espacios que mayor impacto generó en el medio del momento: "Guateque y Son". Luego llegaron coleccionistas de tango reclamando un espacio para su música; a ellos les fue asignada la tarea de pensarlo y hacerlo; la policía ambiental que exigía un espacio de difusión para las acciones ciudadanas en torno a su espacialidad, terminó involucrada cada sábado haciendo radio con sus agentes y colaboradores en un programa que no tenía posibilidad ni siquiera en la emisora de la policía que para esa época funcionaba en Cali. Así todo el que llegó o llamó a solicitar que hablaran de sus intereses, fue invitado y seducido a hacer parte del equipo Comunal. La radio, rompiendo el mito de las voces radiofónicas que suenan bonito y re-dimensionando al locutor convirtiéndolo en radialista ${ }^{38}$, voces que expresan, que dicen cosas simplemente porque tienen cosas qué decir. 


\section{Lecciones aprendidas desde el cierre y el silencio obligado}

Hoy, desde la tranquilidad que deja saber que la suerte de su continuidad como medio de comunicación activo ya está definida, pues no va más, la comunidad reconoce que si bien hoy no se está al aire, hay una serie de legados y lecciones que sin duda podrán dar pie a futuros desarrollos en la radio local y nacional. Hablamos, en primer lugar, de la demostración de que es posible configurar, montar, producir y administrar un medio desde el trabajo y la voz de la propia comunidad. Esto, acompañado de adecuados, pertinentes y oportunos procesos de capacitación en áreas que no se pueden limitar a la producción de discursos radiofónicos. La experiencia demostró que la inocencia y la relativa ignorancia en el campo legislativo hicieron que siempre se tuviese una actitud pasiva y desinformada frente a la normatividad y las formas de promover y exigir políticas públicas claras que más que reprimir, facilitaran la posibilidad de acceder a licencias para hacer radio. En palabras de los mismos actores, se adoptó una postura demasiado pasiva y respetuosa con un Estado que no daba respuestas concisas y contundentes ${ }^{39}$.

Por otro lado, desde el punto de vista de lo administrativo, si bien los esquemas creados le dieron cierta capacidad de organización y movilidad al proceso, algunas estructuras tradicionales fueron demasiado rígidas y poco adecuadas para la naturaleza de un medio de comunicación con una intención tan particular como la de la radio comunitaria. En este sentido, consideraciones de tipo económico que intentaban asegurar la sostenibilidad financiera del medio, desquebrajaron la propuesta política y discursiva de la estación, haciendo que algunas experiencias que aportaban desde los contenidos, no pudieran continuar por no poder cumplir con los aportes solidarios ${ }^{40}$. Hoy, se cree que faltó más espacio para pensar alternativas financieras que evitaran llegar a actitudes de censura y cierre de programas, siguiendo de hecho, las lógicas perversas de la radio comercial a la que tanto se le huía ${ }^{41}$.

Desde el punto de vista de la relación con el entorno, si bien hubo un gran esfuerzo por configurar un discurso que incluyera la cotidianidad, los gustos, los problemas, las ideas y hasta el sueño de ciudad de la comunidad que se tenía como público, faltó generar mecanismos de acercamiento y contacto más directos y conscientes. En este sentido, la condición de radio barrial o comunal, que en un momento del proceso, fue reemplazada por la de proyecto comunicacional de ciudad, hizo que se descartara la necesidad de afianzar los lazos vecinales y las relaciones políticas con los organismos del poder comunal y barrial. Este hecho fue determinante en algunos momentos en los que la debilidad de esas relaciones impidió que la comunidad hiciera una defensa de un espacio al que no sentían suyo: hablamos de las ocasiones en las que sufrieron robos o cuando las amenazas de cierre del Estado se volvieron realidad. En conclusión, hoy saben que la ciudadanía no solo hay que contarla en el discurso radial sino que hay que construirla y fortalecerla desde el trabajo directo con la gente. 


\section{La era digital y su voz en otra voz... posibilidades o resignación}

La última sesión de trabajo con los actores del fenómeno Comunal Estéreo, indagó sobre el futuro del proceso. Si bien la gran mayoría de quienes sostuvieron esa empresa hace 10 años, hoy han iniciado otras apuestas de vida, algunos en el campo de la comunicación, la pregunta sobre el qué hacer o el cómo seguir, está presente. ¿Qué hacer? ¿Abandonarlo todo y dedicarse al trabajo comunitario en otras esferas? ¿Esperar pacientemente 10 años a que se venza la actual concesión y se pueda participar de nuevo o que tal vez un revés de alguna de las que hoy les fueron aprobadas sus licencias les dé la oportunidad de participar antes de la década? o ¿dejar de mirar al pasado y buscar otras alternativas de expresión en aquello que llaman los nuevos caminos de la radio? Han decidido dos cosas para que sus voces no se vayan a callar y como saben que volver a la ilegalidad no es una alternativa mientras el gobierno sea el que se tiene ahora, operarán como productora radial y asesorarán una de las experiencias ganadoras de la licencia que tiene asiento en el Oriente de la ciudad y que además está integrada por algunas de las personas que tuvieron espacios en la emisora y que le apostaron a la misma forma de hacer radio $^{42}$. La otra opción es dar el salto a internet, vía aún desconocida para ellos, pero que se presenta como una gran posibilidad dada la poca regulación que sobre ella existe.

Los espera entonces algo que Mariano Cebrián ${ }^{43}$ denomina más que un salto brusco, una serie de cambios a velocidad vertiginosa que no dan tiempo de asimilar un evento o una transformación cuando ya se tiene que asumir otra innovación. Es la radio que desde comienzos de este siglo, se ha denominado la radio convergente, una radio que se ve obligada a unirse a otros medios, a integrarse y a colmar todas las necesidades y ámbitos del público objetivo, un público que además, ahora es distinto.

Hablamos entonces de una situación que ha llevado a una radio que se resistía a los cambios o que viajaba por ellos de manera lenta, a entrar de lleno en un mundo en el que los medios no se sostienen puros, solos. Una radio que sufre el cambio más importante de su historia, por encima incluso de la invención del transistor que le dio movilidad y la sobrepuso de la aplastante llegada del televisor, o la llegada del FM y la apertura de toda una posibilidad de nuevos sonidos, o la aparición de la estereofonía que le dio volumen y forma a dichos sonidos.

Esta radio convergente, implica no solo cambios en los soportes, trasciende y moldea los modos de producción y, para completar el ciclo, tendrá que moldear los modos de enseñarla e incluso, los modos de estudiarla. Acá nos apoyamos en lo que plantea el profesor español Ángel Faus Belau frente a los cambios que la conjunción que los aspectos tecnológicos, sociales y económicos producen en el medio, definiendo a la radio como un medio frágil en procesos de investigación y hasta de una ciencia propia, inmersa en un sistema caduco de formas de narración, contenidos y conceptos, una radio a la espera de ser reinventada ${ }^{44}$. 
Esta nueva radio es entonces la alternativa más inmediata para Comunal Estéreo, en su afán y para muchos otros hombres y mujeres que anhelan seguir o acceder a la radio como herramienta de comunicación y movilización social y que la ley colombiana ya no se los va a permitir de la forma analógica. Ante todo, porque la radio en esta nueva fase, es liberada por las nuevas tecnologías de la escasez de frecuencias y todos sus compromisos administrativos. Este es sin duda un cambio radical. La técnica se erige como el elemento que supera esta limitación legalista, de forma más precisa en Europa que en nuestros territorios, pero el futuro comienza a mostrarlo como un punto de llegada inevitable. Los satélites, la red y las nuevas tecnologías propugnan usos nuevos que sitúan a la Radio y a los demás medios ante un futuro diferente ${ }^{45}$. Y es en este punto donde retomamos a Cebrián ${ }^{46}$ que desde comienzos de esta década advertía sobre el error de pensar las transformaciones tecnológicas como simples cambios en formatos, obligando a que el análisis atraviese todos estos ámbitos.

Esta mezcla de formatos y tecnologías que involucran a la radio y que hemos denominado la convergencia, enfrenta a su vez, el reto de luchar contra una serie de barreras que algunos de los componentes de esta fusión han vivido de manera particular. Hablamos de la ruptura que se genera, según Girard ${ }^{47}$ desde el diciembre de 1901, fecha en que se estableció la primera transmisión por el hilo de alambre de Marconi, momento en que para unos se abrió la puerta del mundo de la información y para otros, se abrió la brecha digital; esta última para este autor, debe comenzar a sanar y superarse y uno de los primeros pasos para ello, será la fusión de medios disímiles pero encontrados en sus sentidos, como la radio y el internet.

En el caso de nuestros líderes barriales y su nueva aventura, si bien comienza a aclararse la pertinencia de su decisión, hay aún un par de cosas por resolver. La primera tiene que ver con ese oyente al que se va a enfrentar.Ya habíamos expresado como Cebrián reconoce que la transformación tecnológica es como una bola de nieve y está convergencia entonces se implica no solo en la fusión de plataformas sino también en los modos de producción, de negocio y de consumo del mismo medio. Aquellos oyentes fieles que acompañaron el proyecto Comunal desde una forma particular de hacerlo, tal vez no vuelvan más. El oyente invisible al comienzo, pero que después se convierte en asociado, en cómplice o en el radio-participante como lo denominan algunas apuestas de radio alternativa ${ }^{48}$, tiende a adaptarse a las nuevas posibilidades que le ofrece el medio pero también a ser transformado por las particularidades inherentes al mismo. No desaparece se transforma o es transformado. 
A la par con este fenómeno de los nuevos públicos, surge, por ahora, un último elemento a tener en cuenta en esta convergencia mediática a la que colectivos como Comunal Estéreo allá en el Barrio El Guabal, tendrán que enfrentarse en su intención de entrar en las nuevas formas de producción-emisión y consumo. Tiene que ver con el paradigma del conocimiento y las posibilidades de acceso a él en contraste con las condiciones de desarrollo de las comunidades intervenidas por los procesos de la comunicación. Aquí llamamos a escena a Alfonso Gumucio Dagrón, quien no obstante reconocer que internet es la punta de lanza del desarrollo de las comunidades y que nunca antes una tecnología había avanzado tan velozmente en la historia de la humanidad, es importante estar atento a los errores del endiosamiento tecnológico que en el pasado han representado crasos errores y atrasos ${ }^{49}$; advierte entonces que el conocimiento por sí solo no cambiará la situación de desigualdad reinante en los contextos comunitarios ${ }^{50}$. En este sentido, hace un especial énfasis en la necesidad de re-pensar el acceso a las Ntic's no como la gran panacea sino como una herramienta importante que por sí sola, no transforma las realidades sociales. La invitación entonces, es a que en lo relacionado con el acceso a las nuevas tecnologías de la información y su inclusión en los procesos de desarrollo, lo que se genere más que un proceso de tecno fascinación, sea un verdadero proceso de apropiación tecnológica por parte de la gente.

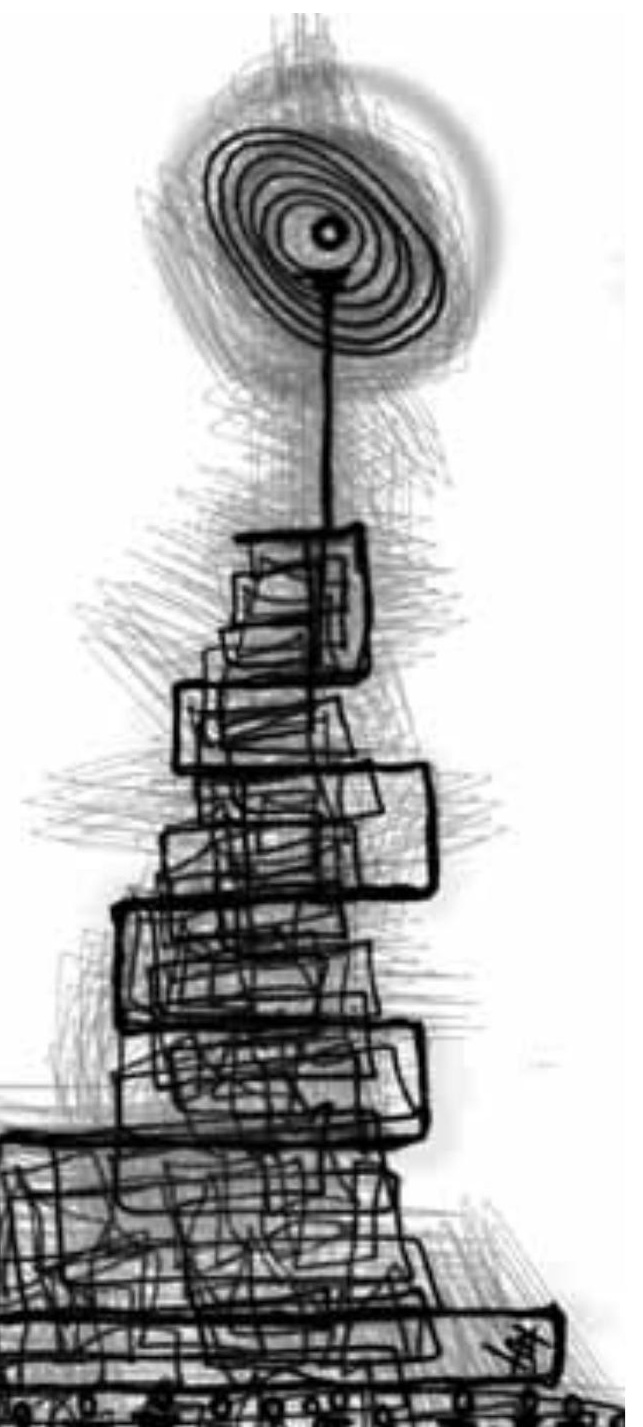

Con este panorama, los actores de Comunal Estéreo tienen hoy un reto importante, pero están tranquilos. Como se lo escucharon a una teórica argentina en el lanzamiento del Plan Decenal de Cultura de Santiago de Cali, los procesos requieren hoy más de preguntas que de certezas ${ }^{51}$. Ahora han empezado a preguntarse ¿cómo caracterizar a estas nuevas audiencias y como invitar a las antiguas a escucharlos de nuevo? ¿Cómo trabajar sin minimizar el impacto que aún genera el desigual acceso a la tecnología por parte de los contextos comunitarios que configuran su audiencia? Pero, igualmente, ¿cómo hablar a nuevos públicos que en su antigua condición y por la limitación tecnológica, no estaban a su alcance? ¿Cuáles serán esos nuevos códigos que hay que descubrir, apropiar o reinventar para contar las historias en los nuevos paradigmas que arroja la convergencia mediática?

Por ahora, han empezado el proceso. Ya han abierto una web gratuita en el servidor Jimdo y a través del manual de nuevas tecnologías para radios comunitarias editado en México por AMARC ${ }^{52}$, han empezado a construir su radio en internet a través de los canales gratuitos de Ustreaming. Lo que venga de ahora en adelante es desconocido pero no temen. Llevan muchos años saltando o esquivando la brecha digital, ha llegado la hora de enfrentarla, es la única forma de saber si se vence o si simplemente, no les toca. 
Sin embargo, la otra certeza es que no obstante ingresar a internet, no van a renunciar a la posibilidad y al derecho de la frecuencia en el aire. Saben que las posibilidades de las nuevas tecnologías abrirán nuevos contextos, públicos y oportunidades, pero también que existen aún y existirán por un buen tiempo en esta parte del mundo, una gran cantidad de personas a las que les está negado el ingreso al internet. Es el público integrado en gran parte por la gente que ayudó a consolidar su propuesta y al que no están dispuestos a renunciar ni a abandonar; por eso continúan atentos a luchar, ahora de manera más organizada y agresiva por el derecho a tener un lugar en el espectro electromagnético, no importa que algunos autores planteen que las nuevas pantallas y canales, vislumbren la muerte de espacios tan legendarios como el libro, la televisión, la radio e incluso el cine. La idea ahora es preparar un proceso de presión al Estado para obligar a que se revise lo que ellos llaman la "poco clara" asignación de la licencia de la zona 3 y que se haga posible nuevamente el proceso de licitación pública de las zonas 1,4 y 5 que fueron declaradas desiertas y en las que saben, podrán recomenzar su proceso en busca de alcanzar eso que Paula Saffon llama el derecho a la comunicación y que lo define como la existencia de espacios tecnológicos pero sobre todo sociales y abiertos para el intercambio de información, el debate y el diálogo democráticos, que faciliten la construcción de consensos e imaginarios colectivos, materializando la participación y fortaleciendo la ciudadanía ${ }^{53}$.

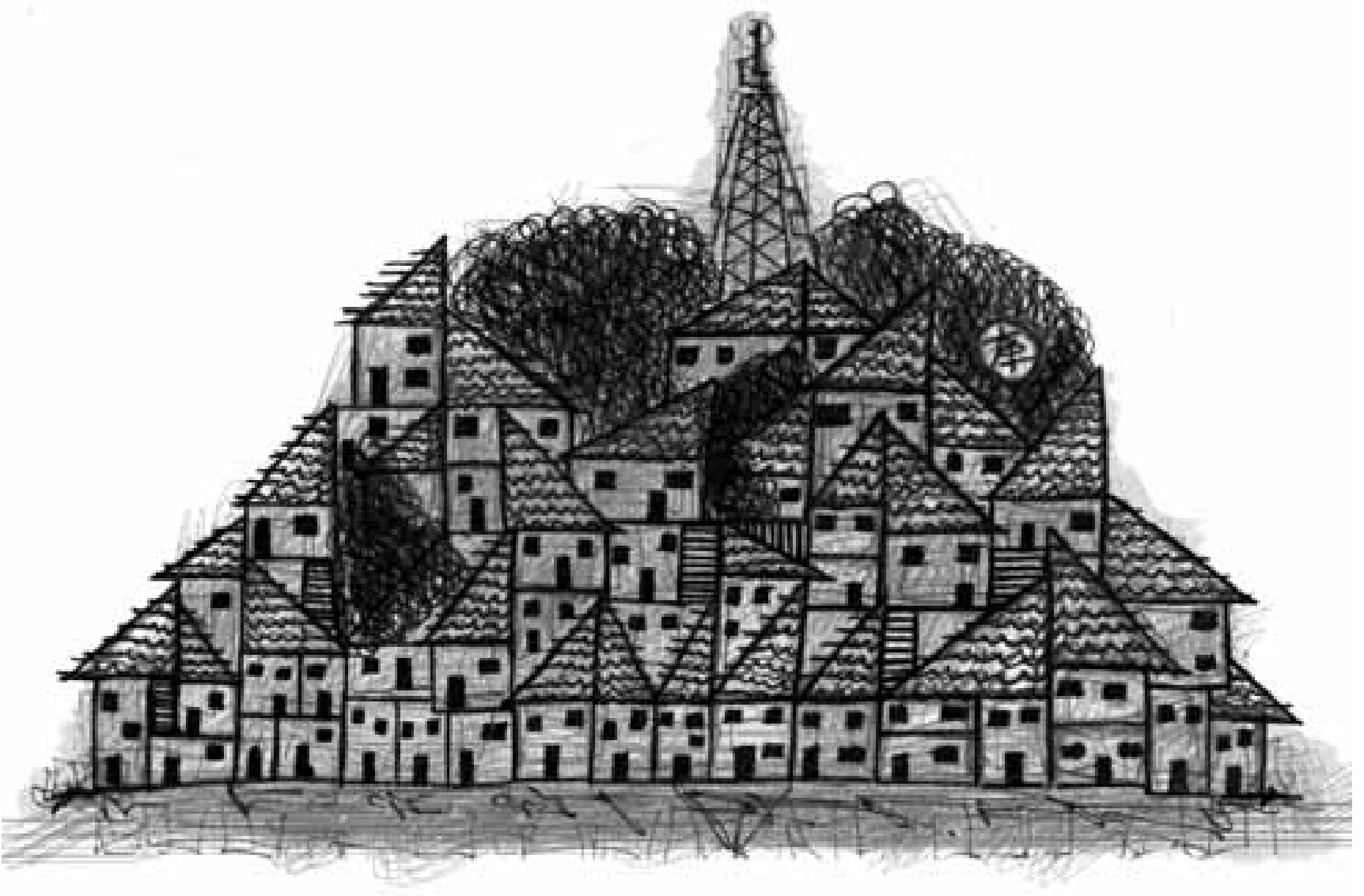


${ }^{8}$ La Asociación Mundial de Radios Comunitarias de la que en varias ocasiones intentó hacer parte sin mucho convencimiento político.

9 ALFARO, Rosa María (1993). Una comunicación para otro desarrollo. Lima, Calandria.

${ }^{10}$ Ministerio de la nuevas tecnologías de la información y la comunicación, antiguo Ministerio de Comunicaciones.

${ }^{11}$ El término inicialmente trabajado por la ley, corresponde a Radiodifusión Sonora Comunitaria, y corresponde a la ley 80 de 1993 y que fue ratificado por el gobierno de Cesar Gaviria Trujillo, en el decreto 1695 de 1994. Según la ley se establece que en Colombia las posibilidades de hacer radio se clasifica en tres modalidades: radio comercial, radio de interés público y radio comunitaria.

${ }^{12}$ YAÑEZ Leonel, "La Radio comunitaria en la transición: transitando desde lo popular a lo cotidiano". En http: / / www.sepiensa.cl/edicion/index.php?option $=$ content\&task $=$ view\&id $=432 \&$ Itemid $=40$ 13 Ídem.

${ }^{14}$ DOWNING, John. "Medios radicales y globalización. PP. 5-15.Códigos.Segunda etapa, volumen 1, número 2, año 1. Otoño 2005. UDLA (Universidad de las Américas), Puebla, México.

${ }^{15}$ En lo que respecta a los procesos comunitarios, José Bernardo Toro, en una conferencia adelantada en Pasto en 1998, en el marco de las Mesas de trabajo sectoriales impulsadas por el Ministerio de Cultura, hacía énfasis de cómo los procesos de radio comunitaria deben moverse en estas dos condiciones: la legalidad que debe llegar del Estado y la legitimidad que debe surgir de la comunidad y de los contextos sociales en los que adelantan su trabajo.

${ }^{16}$ ALFARO, Rosa María. ¿Participación para qué? Un enfoque político de la participación en comunicación popular, en http://www.dialogosfelafacs.net/dialogos_epoca/pdf/22-07RosaAlfaro. pdf

17 PERUZZO Cicilia; "Radio comunitaria, educomunicación y desarrollo social" en http://www. ulima.edu.pe/Revistas/contratexto/v6/pdf/07.pdf

${ }^{18}$ SAFFON, María Paula; "El derecho a la comunicación: un derecho emergente" en "Ya no es posible el Silencio, textos, experiencias y proce3sos de comunicación ciudadana”. Centro de competencia en comunicación para América Latina Friedrich Ebert Stiftung. Bogotá 2007.

${ }^{19}$ MARTÍN BARBERO, Jesús. Tomado de la conferencia “Recuperando lo público para la democracia”.

${ }^{20}$ Término usado por José Freddy Restrepo en la entrevista a profundidad, para graficar la gravedad de las inundaciones que por muchos años, sufrió el sector de la comuna 10 en Cali.

${ }^{21}$ MARTÍN BARBERO, Jesús Martín. Tomado de la conferencia "Recuperando lo público para la democracia”.

${ }^{22}$ WINOCUR Rosalía, “Ciudadanos Mediáticos, la construcción de lo público en la radio”. Gedisa.

${ }^{23}$ MATA María Cristina. "Radios y Públicos populares, investigación”. En revista Diálogos Número

${ }^{19}$. Felafacs. Perú, 1988.

${ }^{24}$ Proceso documentado en la película brasileña "Radio Favela”, inspirada en una historia real.

${ }^{25}$ Revista CHASQUI, número 45, abril de 1993.

${ }^{26}$ VILLEGAS Astrid Elena, RAMÍREZ Nirya, TUNUBALÁ Jeremías, MARTÍNEZ Marta Isabel y ANDRADE María Ilse. "Experiencias, colectivos de comunicación ciudadana en Colombia" en "Ya no es posible el Silencio, textos, experiencias y proce3sos de comunicación ciudadana”. Centro de competencia en comunicación para América Lantian Friedrich Ebert Stiftung. Bogotá 2007.

${ }^{27}$ Ejército Popular de Liberación, que luego asumiera el nombre de Esperanza, Paz y Libertad.

${ }^{28}$ El proceso se desarrolla con la anuencia del Ministerio del Interior que lideraba los procesos de reinserción tanto del EPL como del M-19 y quien, omitiendo los debidos procesos, avaló el inicio de la emisora comunitaria, cuando el resorte de estos permisos, le compete al Mintics, Ministerio de Comunicaciones en su momento.

29 Asociación de Cabildos Indígenas del Valle, Regional Pacífico, que posee en el Puerto de Buenaventura la emisora Radio Chimía y a la que Comunal acompañó con una serie de talleres de diseño y producción radial.

${ }^{30}$ YÁNEZ Leonel; AGUILERA Oscar: "Radios Comunitarias y de Mínima Cobertura: Diagnóstico estado de situación de la radio comunitaria chilena”. Documento trabajo. ECO Educación y Comunicaciones. Santiago de Chile, Marzo, 2001. 
31 Término introducido por Jesús Martín Barbero que definía como “...una multiplicidad de paradojas densas y desconcertantes: la convivencia de la opulencia comunicacional con el debilitamiento de lo público, la más grande disponibilidad de información con el palpable deterioro de la educación formal, la continua explosión de imágenes con el empobrecimiento de la experiencia, la multiplicación infinita de los signos en una sociedad que padece el más grande déficit simbólico. La convergencia entre sociedad de mercado y racionalidad tecnológica disocia la sociedad en 'sociedades paralelas': la de los conectados a la infinita oferta de bienes y saberes y la de los excluidos cada vez más abiertamente tanto de los bienes más elementales como de la información exigida para poder decidir como ciudadanos. La tecno-fascinación contiene también a esa cultura de la privatización que ha convertido la política en intercambio y negociación de intereses y al mercado en el principio organizador de la sociedad en su conjunto, en un movimiento de auto-legitimación que hace coincidir la autonomía del sujeto con el ámbito de la privacidad y del consumo”. En "Cultura, medios y sociedad".

${ }^{32}$ RODRÍGUEZ, Clemencia. Tres lecciones aprendidas de los medios ciudadanos y comunitarios en Colombia. PP. 1-14. Ponencia presentada en el Encuentro Nacional de Medios Ciudadanos, organizado por el Ministerio de Cultura, Julio 11-14, 2006.

${ }^{33}$ El espacio radial La S.O.N.A (Sistema Organizativo Nacional de Artistas) emitido por Comunal , y su posterior desarrollo audiovisual y de gestión, denominado "Cruzando la Calle", se convirtió en una experiencia de intervención y movilización social, que desde la comunicación alternativa, le apostó a mostrar como esa línea imaginaria que divide al Distrito de Aguablanca con el resto de la ciudad, podría tener una serie de connotaciones negativas, discriminantes y excluyentes, pero a su vez, podría ser el inicio de una experiencia de inclusión y de diálogo cultural.

${ }^{34}$ HUERGO Jorge, MORAWICKI Kevin y FERRERIRA Lourdes; "Una Experiencia con aborígenes wichi, los medios, las identidades y el espacio de comunicación”. En Revista Comunicar, número 26. 2006.

${ }^{35}$ En términos de Borja y Castells, hablamos de la ciudad dual. La ciudad de los flujos de comunicación que intentan unir, una ciudad fragmentada, la de los lugares reales.

${ }^{36}$ RODRÍGUEZ, Clemencia. "Tres lecciones aprendidas de los medios ciudadanos y comunitarios en Colombia”. Ponencia presentada en el Encuentro Nacional de Medios Ciudadanos. Bogotá Julio 2006.

37 TOFLER Alvin y TOFLER Heydi. Las Guerras del futuro. Plaza \& Janes, 1994.

38 Término acuñado por José Ignacio LópezVigil, que define a los hombres y mujeres que asumen la radio como un espacio de expresión, de movilización social, de discusión y de propuesta y van más allá de las voces bonitas o educadas (sin excluirlas), que se preocupan más por el Cómo suenan que por el Qué dicen.

39 Calambás Alcibíades. Entrevista a profundidad.

40 Ante la imposibilidad legislativa y por principios de su plataforma estratégica, de alquilar espacios como en las dinámicas comerciales, la experiencia Comunal concertó un sistema de aportes solidarios en los que las organizaciones que tenían espacios radiales, aportaban un monto mensual para contribuir con el sostenimiento financiero de la sede y de la nómina de operadores y equipo administrativo de base.

${ }^{41}$ Ruiz, Robinson, Entrevista.

42 Se trata de la Asociación Agencia Red Cultural del Distrito de Aguablanca, que en su momento, desarrolló en la emisora espacios radiales de difusión de la música del Pacífico e informativos culturales sobre la comunidad del oriente caleño y que participara y ganara la licencia de transmisión comunitaria para la zona 2 de Cali, asesorada por el equipo directivo de Comunal Estéreo.

${ }^{43}$ CEBRIÁN HERREROS, Mariano. "La radio en la era de la convergencia multimedia". Barcelona, 2001. 
${ }^{44}$ FAUS BELAU, Ángel. “Reinventar la Radio”. En: “Chasqui”. Número 74. 2001.

${ }^{45}$ BELLANGUER citado en FAUS BELAU, Ángel. "Reinventar la Radio”. En: "Chasqui”. Número 74. 2001.

46 CEBRIAN HERREROS. Op. cit

47 GIRARD, Bruce. La radio no está amenazada por internet. En revista digital Chasqui. En http: / / chasqui.comunica.org/girard70.htm

48 Tomado del documental FM ALAs, referido a una experiencia de radio alternativa argentina; documental producido por el equipo humano de Radio FM La Tribu en http: / www.youtube.com/ watch?v $=$ ufrtmV8iqzQ

49 GUMUNCIO DAGRON, Alfonso. "Las cinco condiciones esenciales para las TICs en el desarrollo”. En Secreto a Voces: Radio, Nuevas tecnologías de información y comunicación (NTICs) e interactividad. Editado por Bruce Girard, en http: / / comunica.org/secreto/pdf/secreto.pdf ${ }^{50}$ Ibíd.

${ }^{51}$ Apuntes propios tomado de la conferencia dictada por RosalíaWinocour en el foro "De las políticas culturales a los barrios. Representaciones y prácticas ciudadanas sobre la cultura”, desarrollado en Cali, en el mes de febrero de 2010, en el marco del lanzamiento del Plan decenal de Cultura.

52 "Manual de Nuevas Tecnologías para radios Comunitarias”. AMARC-México.

53 SAFFON, María Paula; "El derecho a la comunicación: un derecho emergente" en "Ya no es posible el Silencio, textos, experiencias y proce 3 sos de comunicación ciudadana”. Centro de competencia en comunicación para América Latina Friedrich Ebert Stiftung. Bogotá 2007.

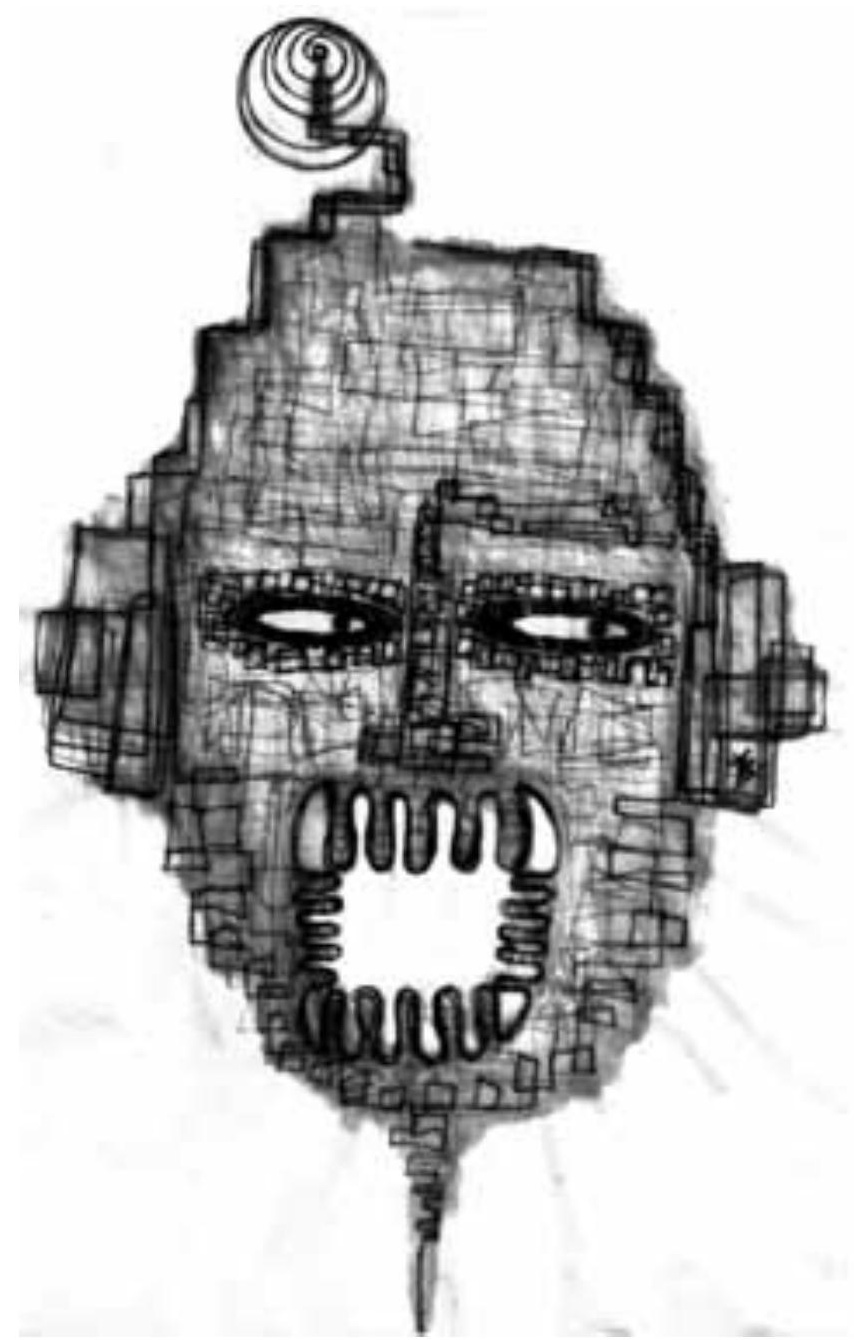




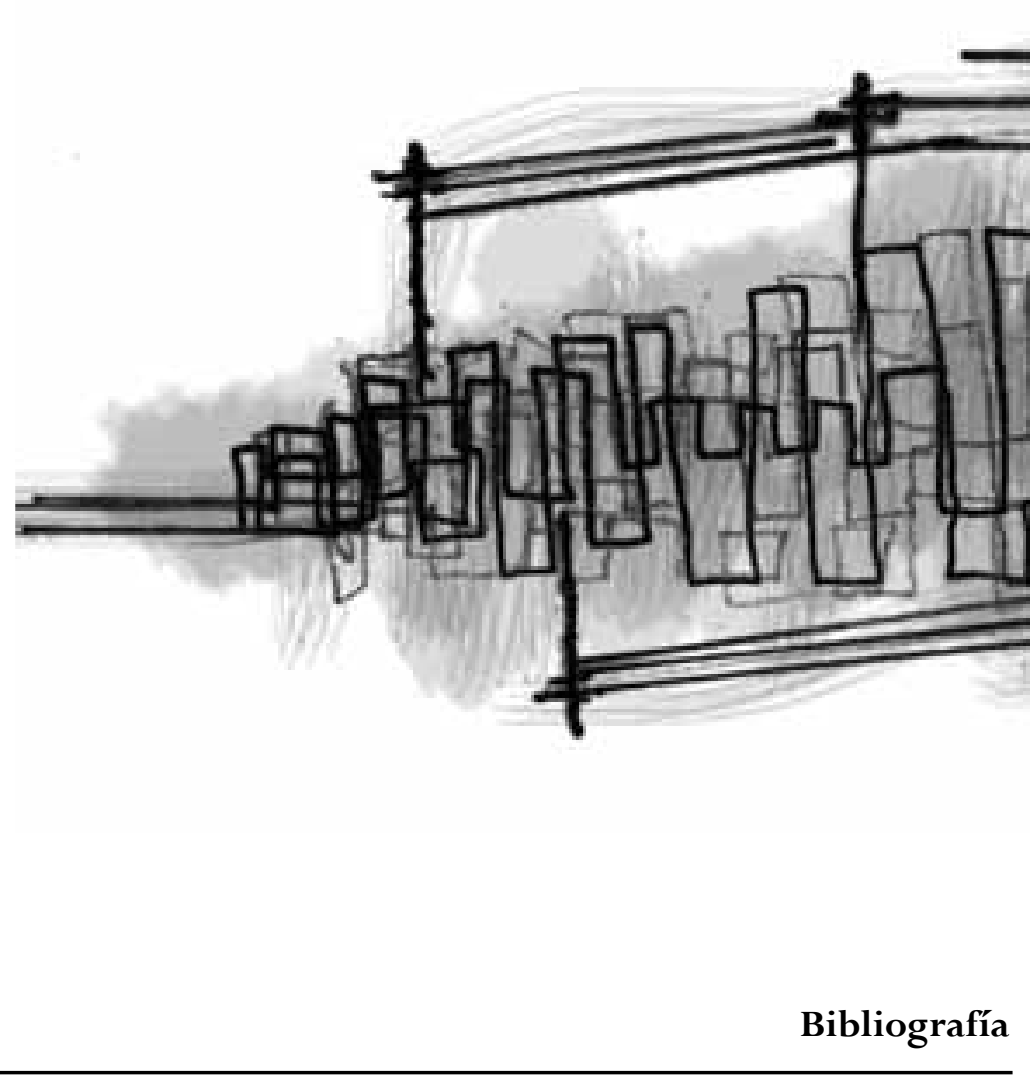

Bibliografía

ALER (1993). Prender para aprender, uso de la radio en la educación. Quito, 1993ALFARO, Rosa María. Una comunicación para otro desarrollo. Lima, Calandria

ALFARO, Rosa María; TELLEZ, Rubén, PINILLA, Helena; GOGIN Gina(1990). Cultura de masas y cultura popular en la radio peruana. Tarea. Lima, Perú.

BOOTH, Jerry; LEWIS, Peter (1992). El medio invisible, radio pública, privada, comercial y comunitaria. Paidos. Buenos Aires.

BORJA, JORDI \& CASTELLS Manuel (1988). Local y Global, la gestión de las ciudades en la era de la información. Taurus. España.

CEBRIAN HERREROS, Mariano (2001). La Radio en la Convergencia Multimedia. Gedisa. Barcelona. DOWNING, John (2005). "Medios radicales y globalización. PP. 5-15.Códigos.Segunda etapa, volumen 1, número 2, año 1. UDLA (Universidad de las Américas), Puebla, México

FUNDACION SOCIAL. Señales de Humo, panorama de la televisión local y comunitaria en Colombia. Cinep. Bogotá, 1998.

GUMUCIO DAGRON, Alfonso (2001). Haciendo Olas, historia de la comunicación participativa para el cambio social.The Rockefeller Foundation. NuevaYork.

INSTITUTO POPULAR DE CULTURA, Referencias para pensar la gestión de las culturas populares locales. Cali, 2009.

RECORRA. IV Encuentro nacional de radios comunitarias - Memorias. Ministerio de Cultura, Colombia, 2000.

SAFFON, María Paula y otros (2007). Ya no es posible el Silencio, textos, experiencias y procesos de comunicación ciudadana". Centro de competencia en comunicación para América Latina Friedrich Ebert Stiftung. Bogotá.

TOFLER Alvin y TOFLER Heydi (1994). Las Guerras del futuro. Plaza \& Janes.

VINETTI, Natalia; RODRIGUEZ ESPERON, Carlos (2004). Contraiformación, medios alternativos, para la acción política. Ediciones Continente.

WINOCUR, Rosalía (2002). Ciudadanos Mediáticos, la construcción de lo público en la radio. Gedisa. Barcelona.

YÁNEZ Leonel; AGUILERA Oscar (2001): "Radios Comunitarias y de Mínima Cobertura: Diagnóstico estado de situación de la radio comunitaria chilena”. Documento de trabajo. ECO Educación y Comunicaciones. Santiago de Chile. 